\title{
Global Health, Cancer Challenges and Control in African Settings
}

\author{
Adama Ly* \\ International Network against Cancer, University Paris XI, Europe
}

Submission: October 12, 2016; Published: November 01, 2016

"Corresponding author: Adama Ly, Afrocancer, International Network against Cancer and University Paris XI, Afrocancer, BP 60751, 75827 Paris Cedex

17,France, Europe, Email: adamaly@gmail.com

\begin{abstract}
The problem of cancer in Africa is so dire that international institutions are predicting " a new scourge on a huge scale, one which, both directly and through its enomic impact, will increase poverty, misery and the death rate". A comprehensive policy response is therefore urgently needed and it's a duty to unravel the assertion that theses pathologies are restricted to high income nations. A global and coherent health program must be built and implemented at the national, regional and continental levels. To address this epidemiologic challenge, one the first steps will be the international cooperation and coordination based on resolute actions and programmes.
\end{abstract}

Keywords: Cancer, Africa, developing countries, Non Communicable Diseases, Global health

\section{Introduction}

Even in developing countries such as African countries non communicable diseases (NCDs) are among leading causes of death. It's a duty to unravel the assertion that theses pathologies are restricted to high income nations. Admittedly, Human immunodeficiency virus infection and acquired immune deficiency syndrome (HIV/AIDS), Malaria, Tuberculosis, Ebola virus disease (EVD) and other endemic tropical sicknesses have had the priority in health's political agenda. Nevertheless, it will be an unrecoverable error to underestimate the seriousness of this scourge [1-3].

Abbreviations: HIV/AIDS: Human Immunodeficiency Virus and Acquired Immune Deficiency Syndrome; NCDs: Non Communicable Diseases; EVD: Ebola Virus Disease; IARC: International Agency for Research on Cancer; WHO: World Health Organization; UN: United Nations; AU: African Union; NTD: Neglected Tropical Diseases; SCCA: Stop Cervical, Breast and Prostate Cancer in Africa; MDGs: Millennium Development Goals; SDGs: Sustainable Development Goal; SSA: Sub-Saharan Africa; GDP: Gross Domestic Products

\section{Cancer Statistics}

Instead of the lack of reliable cancer registries in many African regions, the International Agency for Research on Cancer (IARC) latest statistics on cancer trends worldwide exhibit a pessimistic and critical outlook: 8 million of new cancer cases (57\%), 5.3 million of the cancer deaths (65\%) and 15.6 million $(48 \%)$ of the 5 -year prevalent cancer cases occurred in developing countries [4,5]. In Africa, the cancer incidence has been estimated to 847.000 new cancer cases and 591.000 patients died from cancer. In women, the three most common cancers are breast, cervical and liver malignant tumours. In men, prostate, liver cancers and Kaposi sarcoma are the three most frequent malignancies [4,5]. Cancer causes worries, suffering and millions of deaths across the globe and is a great concern to modern society: "There were 14.1 million new cancer cases, 8.2 million cancer deaths and 32.6 million people living with cancer (within 5 years of diagnosis) in 2012 worldwide" [4]. For reasons that are both complex and multi factorial, ranging from chronic infections, the change in lifestyles and living conditions to environmental pollutions and from structural changes in the population (demography and aging) to heredity, cancer has grown in every continent $[1,4,5]$ (Table 1 ) (Figure 1). 


\section{Cancer Therapy \& Oncology International Journal}
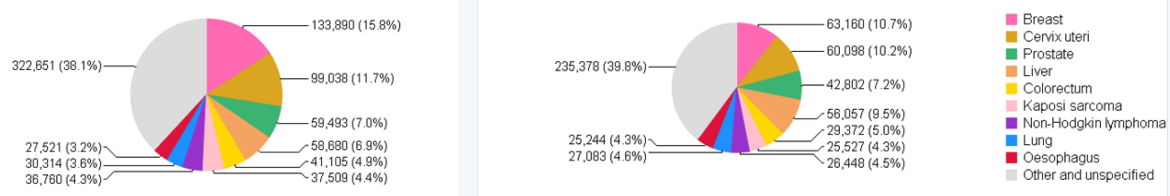

Figure 1a*: Incidence by type (both sexes).

*GLOBOCAN 2012 v1.0, Cancer Incidence and Mortality Worldwide: IARC Cancer Base No. 11. Lyon, France: International Agency for Research on Cancer.

Figure $\mathbf{1 b}^{*}$ : Mortality by type (both sexes).

Figure 1: Incidence and mortality of cancer in Africa (all cancer exclusion of melanoma skin cancers).

Table 1: Cancer statistics in Africa (2012) ${ }^{*}$

\begin{tabular}{|c|c|c|c|}
\hline Africa & Male & Female & Both sexes \\
\hline Population (thousands) & 536179 & 536226 & 1072406 \\
\hline $\begin{array}{c}\text { Number of new cancer } \\
\text { cases (thousands) }\end{array}$ & 362.0 & 484.9 & 847.0 \\
\hline $\begin{array}{c}\text { Age-standardised rate } \\
\text { (W) }\end{array}$ & 115.6 & 132.4 & 123.4 \\
\hline $\begin{array}{c}\text { Risk of getting cancer } \\
\text { before age 75 (\%) }\end{array}$ & 12.3 & 13.4 & 12.8 \\
\hline $\begin{array}{c}\text { Number of cancer deaths } \\
\text { (thousands) }\end{array}$ & 277.8 & 313.3 & 591.2 \\
\hline $\begin{array}{c}\text { Age-standardised rate } \\
\text { (W) }\end{array}$ & 92.9 & 88.7 & 89.8 \\
\hline $\begin{array}{c}\text { Risk of dying from cancer } \\
\text { before age 75 (\%) }\end{array}$ & 9.5 & 9.4 & 9.4 \\
\hline $\begin{array}{c}\text { 5-year prevalent cases, } \\
\text { adult population } \\
\text { (thousands) }\end{array}$ & 631.7 & 1148.4 & 1780.1 \\
\hline Proportion (per 100,000) & 198.3 & 354.6 & 277.1 \\
\hline $\begin{array}{c}\text { 5 most frequent cancers } \\
\text { (ranking defined by total } \\
\text { number of cases) }\end{array}$ & Prostate & Breast & Breast \\
\hline Liver & Cervix uteri & Cervix uteri \\
\hline sarcoma & Liver & Prostate \\
\hline Colorectum & Colorectum & Liver \\
\hline Colorectum \\
\hline
\end{tabular}

\section{Risk factors, NCDs and tropical sicknesses}

The prevalence and characteristics of cancers vary, particularly in terms of social and economic development of a given country. Thus, developed and developing nations have their own specificities. In northern countries, exposure to the sun, smoking, eating habits, lack of physical activity, excessive consumption of alcohol and, to a lesser degree, heredity and viral infections, are the principal causes of cancer. Furthermore, urban development and frenetic industrialization are responsible for the increase in cancer risks. Indeed, physical carcinogens (radioactivity) or chemical ones (asbestos, hydrocarbons, nitrates) and phytosanitary products are deleterious environmental pollutants resulting from anthropogenic activities whose breadth of impact on human health has not yet been measured. Besides these risk factors, in Africa, there are strong demonstrated links between cancers and tropical diseases contributing to lower the life expectancy of populations.

Then, African populations are suffering from both types of illnesses: communicable and non communicable diseases. Health matters are going from bad to worse. When superimposed on parasitic and communicable diseases which chronically affect millions of individuals, the tremendous health pressure contributes to reducing quality of life and life expectancy, which could decrease by 20 years in some countries according to World Health Organization (WHO) $[1,4,5]$. Schistosomiasis, malaria, viral hepatitis (B and $\mathrm{C}$ ) and other tropical diseases are objective allies of cancer, feeding a vicious circle which reduces to nothing all of the tireless efforts and attempts to establish better public health for the benefit of social and economic development. These parasitoses and viral infections spread endemically in this part of the world and interact with other factors to lay the ground for the emergence or promotion of certain types of cancer such as Burkitt's lymphoma, bladder tumors, malignant hepatomas, and cervical cancer. Stomach cancer is associated with a bacterial infection due to helicobacter pylori and a mycotoxin (Aflatoxin B1), secreted by a filamentous fungus, Aspergillus flavus is involved in the oncogenesis of hepatic cancers affecting Africans. These demonstrated and admitted scientific facts are against some arguments that malignancies are not a health priority in African Sub-Saharan countries [1,3-5].

\section{Global health and sustainable development goals}

This paper also wanted to debunk this argument or myth that is always put forward. The fundamental roots and the crucial determinants of the cancer burden in Africa and less developed countries have to be attacked.

As said the Assistant Director-General of Non Communicable Diseases and Mental Health at World Health Organization "in the developed western countries the situation remains under 


\section{Cancer Therapy \& Oncology International Journal}

control, as things stand, but for the poor, less developed countries it might turn into a new scourge on a huge scale, one which, both directly and through its economic impact, will increase poverty, misery and the death rate." [6]. To address this epidemiologic challenge, one the first steps will be the international cooperation and coordination based on resolute actions and programmes. To achieve these goals, the international political will, determination and implication is undoubtedly required. At the international level, encouraging efforts and decisions began with the Moscow Declaration on NCDs, endorsed by Ministers of Health in May 2011 and the United Nations (UN) Political Declaration on NCDs endorsed by Heads of State and Government in September 2011. In order to respect these engagements, the World Health Assembly endorsed the WHO Global Action Plan for the Prevention and Control of NCDs 2013-2020 in May 2013 [7].

At the African level, the African Union (AU) reaffirmed its political will and commitments to fight the spread of cancers and other NDCs by taking several resolutions as at the Sixth Conference of AU Ministers of Health held in Addis Ababa in Ethiopia from 22nd to 26nd April 2013 with the following theme "The Impact of Non-Communicable Diseases (NCDs) and Neglected Tropical Diseases (NTD) on Development in Africa" or more recently at The 10th Stop Cervical, Breast and Prostate Cancer in Africa (SCCA) Conference [8]. Globally, health issues have been taken into consideration in the eight Millennium Development Goals (MDGs). Four out of eight items were child mortality and maternal health, hunger, malaria and HIV/ AIDS [9]. However, the MDGs of the last decade didn't pay any attention to cancers and other non communicable diseases. In the post2015 Sustainable Development Goal (SDGs), it's recognized that health is an important pillar of sustainable development as are climate change and food security. In each country, a wide range of 17 goals must be implemented and achieved in fourteen years (2016-2030) [10].

Even so, the achievability of these goals in low and middle income countries has to be questioned. We have to keep in mind that most countries in sub-Saharan Africa (SSA) have not achieved or partially achieved the millennium development goals. The main reasons of such failures are poverty, political instability, mismanagement, corruption, illiteracy, analphabetism $[10,11]$. For instance, in 2002, in the Abuja declaration, African governments have committed to spending $15 \%$ of their gross domestic products (GDP) or their national budgets on health. Since then, the vast majority of the African Union members have not fulfilled their commitment [12]. In addition, the weakness of health systems (human resources, drug availability, technical platform, health inequities, social insurance, and health funds) is an enormous impediment to the route for better health outcomes from cancer and NCDs. A successful completion of such goals for sustainable development remains, obviously, a high priority especially in social and health fields.

\section{Cancer economics}

If the social impact and the morbidity of cancer are clear-cut, the economics of this pathology are also alarming. In 2010, the overall annual financial statement of cancer was estimated to 1.16 trillion USD $[4,13]$. The cost of the 13.3 millions new cancer cases, in 2010, was evaluated to 290 billion US Dollars. The medical cost was estimated to 154 billion and the non medical costs accounting are assessed to 67 billion US Dollars. As regards the income losses, it has reached 69 billion US Dollars. In the near future, according to the WHO, by year 2030, the global cost will rise by 458 billion US Dollars given the population aging trends worldwide [13]. Once again, the burden of cancer is significantly supported by poor and emerging countries: $47 \%$ of the incidence and $55 \%$ of the mortality are occurring in these countries that are facing a huge challenge to fight this scourge [14]. In the meanwhile, the basic package of cost effective strategies to target and to notably reduce the common cancer risk factors in those nations should require a financial effort as small as 2 billion US Dollars per year [15]. Nevertheless, up to now, surprisingly and strangely, only $3 \%$ of the aid for health development from developed nations is spent in cancer and other NCDs control [14].

\section{Integrated actions with other NCDs and transversal programs}

In short, cancer has a tremendous negative impact in the social and economic situations of emerging and developing countries. As a matter of fact, a comprehensive and coherent health program must be built and implemented at the national, regional and continental levels. Since NCDs (cancers, cardiovascular diseases, chronic respiratory diseases diabetes) share many common risk factors (obesity, harmful use of alcohol, tobacco consumption, physical inactivity, malnutrition) an integrated program would be the appropriate and relevant approach to combat cancer in African countries $[6,16]$. Furthermore, cancer determinants are behavioral, cultural, social, cultural, environmental and political. The health policies and strategies wouldn't be only technical although improving access to essential medicines, radiotherapy, vaccines, biomedical and imaging technologies are vital. As a result, some tentative responses have to be local and specific, adapted to the continent realities and must include as much as possible local human resources [16-20]. Vertical programs designed to tackle a specific disease with a specific risk factor are nowadays obsolete or irrelevant to uproot the cancer and NCDs outbreak and expansion [17-20]. The Epidemiologic transition is factual in the African landscape and certainty leaves no room for doubt.

\section{Conclusion}

Despite many and various internal obstacles, there's a growing associational network (local voluntary sector, civil society, non-governmental organizations (NGOs), patients and 


\section{Cancer Therapy \& Oncology International Journal}

their families ,community leaders, health professionals, African diasporas) involved in the fight against cancer throughout the continent which is striving to be a great part of the solutions $[1,16,18,19,21,22]$. Hope lies there too. As said the German philosopher and poet Friedrich Hölderlin (1770-1843), "Where increases the danger grows also what saves" [23]. In any case, with the existing knowledge (public awareness, early diagnosis and treatment, drug affordability, capacity building, scientific and technical infrastructures improvements) it's utterly possible to drastically, technically and humanely scale down the cancer disaster in African developing countries and save thousands of human lives.

\section{References}

1. Adama Ly, David khayat (2006) About cancer in Africa: from epidemiology to biomedical applications and perspectives with the preface of Pr. Jean Dausset.

2. Lopez AD, Williams TN, Levin A, Tonelli M, Singh JA, et al (2014) Remembering the forgotten non-communicable diseases. BMC Med 12(1): 200.

3. Shah Ebrahim, Liam Smeeth (2005) Non-communicable diseases in low and middle-income countries: a priority or a distraction? Int J Epidemiol 34(5): 961-966.

4. Stewart BW, Wild CP (2014) World Cancer Report 2014.

5. Ferlay J, Soerjomataram I, Ervik M, Dikshit R, Eser S, et al. (2013) GLOBOCAN 2012 v1.0, Cancer Incidence and Mortality Worldwide: IARC Cancer Base No 11.

6. WHO (2013) Global action plans for the prevention and control of non communicable diseases 2013-2020.

7. WHO (2013) Follow-up to the Political Declaration of the High-level Meeting of the General Assembly on the Prevention and Control of Non-communicable Diseases.

8. Sixth Conference of AU Ministers of Health (2013) Addis Ababa, Ethiopia.

9. United Nations Millennium Development Goals (2000).

10. United Nations sustainable development goals (2015).
11. Cary Adams and Rebecca Morton Doherty (2014) Beyond the Millennium Development Goals: Positioning cancer control in the post2015 agenda in Cancer Control 2014: Cancer care in emerging health systems p 26-30.

12. WHO (2011) Abuja declaration: Ten years on.

13. Bloom DE, Cafiero ET, Jané-Llopis E, Abrahams-Gessel S, Bloom LR, et al. (2013) The Global Economic Burden of Non communicable Diseases. World Economic Forum 1-46.

14. A. Nugent RA, Feigl AB (2010) Where have all the donors gone? Scarce donor funding for non-communicable diseases working Paper 228; B. Muka T, Imo D, Jaspers L, Colpani V, Chaker L, et al. (2015) The global impact of non-communicable diseases on healthcare spending and national income: a systematic review. Eur J Epidemiol 30(4): 251-277; C. Hill PS, Buse K, Brolan CE, Ooms G (2014) How can health remain central post-2015 in a sustainable development paradigm? Global Health 10: 18.

15. WHO (2011) Scaling up action against non communicable diseases: How much will it cost?

16. A Ly (2013) A plan of action to turn down the inevitability of death through cancer in Africa. J Afr Cancer 5: 181.

17. Sasco, Annie J, Jaquet, Antoine, Dabis (2011) Cancer and HIV in Sub-Saharan Africa: Not Exactly as in the North Journal of Acquired Immune Deficiency Syndromes 56(42).

18. McCarthy M, Maher D, Ly A, Ndip A (2010) Developing the agenda for European Union collaboration on non communicable diseases research in Sub-Saharan Africa. Health Research Policy and Systems 8: 13.

19. BS Sylla, CP Wild (2012) Cancer burden in Africa in 2030: Invest today and save tomorrow. J Afr Cancer 4(1): 1-2.

20. Frenk J, Gómez-Dantés O, Moon S (2014) From sovereignty to solidarity: a renewed concept of global health for an era of complex interdependence. Lancet 383: 94-97.

21.The Lancet Global health (2016) Financing for health: where there's a will. 4(10): e663.

22. Stefan DC, Elzawawy AM, Khaled HM, Ntaganda F, Asiimwe A, et al (2013) Developing cancer control plans in Africa: examples from five countries. Lancet Oncol 14 (4): e189 - e195.

23. Friedrich Hölderlin (2004) Poems and Fragments translated by Michael Hamburger. pp 823.

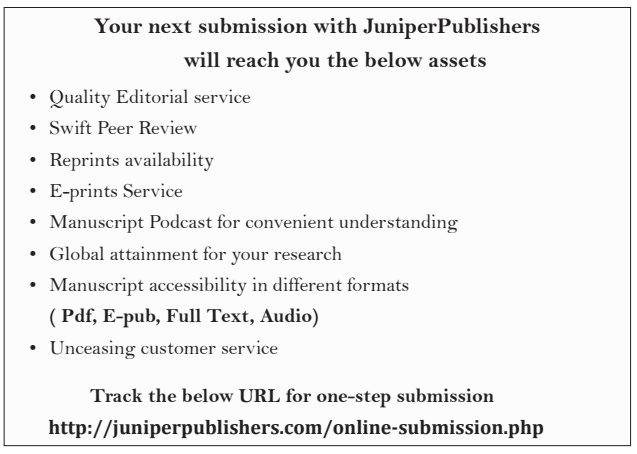

